\title{
The climate benefits of yield increases in genetically engineered crops
}

Emma Kovak ${ }^{* 1}$, Matin Qaim², and Dan Blaustein-Rejto ${ }^{1}$

${ }^{1}$ The Breakthrough Institute, Oakland, CA, USA ${ }^{2}$ Department of Agricultural Economics and

Rural Development, University of Goettingen, 37073 Goettingen, Germany

*email at ekovak@thebreakthrough.org 


\section{Abstract}

2 The benefits of genetically engineered (GE) crops are systematically underestimated

3 because previous studies did not incorporate the reduction in greenhouse gas (GHG)

4 emissions associated with yield increases. We estimate this impact using the carbon

5 opportunity cost of land use. Our results suggest that the GHG emissions reductions

6 from the yield increases in GE crops are substantial and should be included in future

7 analyses.

8

9 Previous studies quantified the economic benefits of GE crops, including increases in crop

10 yields and profits, as well as the environmental and health benefits resulting from reduced

11 pesticide use ${ }^{1,2}$. Lower GHG emissions from reduced tillage and savings in the use of tractor

12 fuel were also considered ${ }^{3}$. However, reductions in GHG emissions associated with yield

13 increases in GE crops were not quantified. As global demand for food and other agricultural

14 products continues to grow, crop yield increases reduce the need to add new land into

15 production, thus preventing additional $\mathrm{CO}_{2}$ emissions ${ }^{4}$ (Fig. 1). Land-use change accounts for

16 almost half of all GHG emissions from agriculture ${ }^{5}$.

18 Here, we calculate the climate benefits of yield increases in GE crops, building on a method 19 developed by Searchinger et al. $(2018)^{6}$. We estimate to what extent GHG emissions could 20 have been avoided if the European Union's (EU) level of adoption of GE varieties of five major

21 crops (maize, soybean, cotton, canola and sugarbeet) had been equal to that of the USA

22 (Methods and Supplementary Tables 1 and 2).

24 While the climate benefits of GE crops can be calculated globally, we concentrate on the EU for 25 two reasons. First, the EU has not yet widely adopted GE crops, mostly due to issues with 26 public acceptance and related political hurdles ${ }^{1}$. This means that we can compare a hypothetical 
27 scenario with GE crop adoption to the status quo where hardly any GE crops are grown.

28 Second, the EU is currently undergoing a reassessment of its GE policies (following Council

29 Decision 2019/1904), and this analysis could help provide a more comprehensive picture of the

30 likely effects of policy change.

Based on previous research we know that GE crops can increase yields, and we would expect this effect if the EU adopted GE crops. While various GE crop traits have been developed, the most widely adopted ones in different parts of the world are insect resistance (IR) and herbicide tolerance $(\mathrm{HT})^{1,7}$. These traits help to reduce crop damage from insect pests and weeds, thus increasing effective yields. A global meta-analysis showed that the average yield advantages of GE crops are around $22 \%$, with some differences between traits and geographical regions ${ }^{8}$. The average yield increase from GE adoption in temperate-zone industrialized countries is $9.7 \%$ and $6.5 \%$ for IR and $\mathrm{HT}$, respectively ${ }^{8}$.

If EU crop yields increase with the hypothesized adoption of GE traits, we would expect this increased production in the EU to lead to a decrease in production and related land-use change elsewhere. In our analysis we consider two components of GHG emissions: the carbon

44 opportunity cost (COC) of land use and production emissions (PEM). The COC is defined as the

45 land's opportunity to store carbon if it is not used for agriculture. This is influenced by the

46 average carbon stocks in the native vegetation and in the soil, as well as the global average

47 yield of each crop. Higher carbon stocks mean higher potential emissions from clearing land.

48 Hence, shifting production towards places with yields above the global average - such as the

49 EU - enables greater carbon storage on spared land elsewhere. PEM are calculated based on

50 fertilizer and energy input use in production. 
52 We find that growing GE crops in the EU could reduce GHG emissions by 33 million metric tons

53 of $\mathrm{CO}_{2}$ equivalents per year $\left(\mathrm{MtCO}_{2} \mathrm{e} / \mathrm{yr}\right)$. This is equivalent to $7.5 \%$ of total EU agricultural $\mathrm{GHG}$

54 emissions in $2017^{9}$. The avoided emissions per hectare are higher for maize than for the other

55 crops (Fig. 2a), which is due to the fact that GE varieties with stacked IR and HT traits, and thus

56 higher yields, are widely available for maize. Maize also accounts for the largest share (63\%) of

57 the total GE-related emission reductions in the EU (Fig. 2b, Supplementary Table 3), because

58 maize is grown on larger areas than the other four crops considered. For all five crops, COC

59 makes up a much larger proportion (>84\%; Supplementary Table 3) of the total potential

60 avoided GHG emissions than PEM, underlining the importance of considering COC when

61 estimating the climate impacts of agricultural production and policy changes. For soybean, the

62 smallest PEM reductions occur because average soybean PEMs in the EU are higher than the

63 global average.

65 Our analysis builds on a few assumptions that may lead to certain inaccuracies in the estimates.

66 For instance, we assume that increased crop production in the EU leads to a proportional

67 decrease in production elsewhere. While significant global land-sparing effects of crop yield

68 increases are clearly established ${ }^{4}$, the magnitude can vary and is difficult to predict precisely in

69 a particular situation ${ }^{10,11}$. Our assumption of a proportional link may lead to overestimation of

70 avoided emissions. However, this is likely compensated for by two other assumptions that lead

71 to underestimation. First, we assume that increasing GE crop adoption in the EU would have no

72 effects on technology adoption in other countries, even though the quasi-ban of GE crops in the

73 EU over the last 20 years has also discouraged their use elsewhere ${ }^{1}$. Hence, higher GE crop

74 adoption in the EU would likely also lead to higher adoption elsewhere, including in Africa and

75 Asia. Second, although we only consider mitigation potential in 2017 based on the adoption of

76 IR and HT traits in five crops available at the time, future adoption of more GE crops and traits

77 will likely increase emissions reductions, especially with more conducive EU policies. 
79 Restrictive regulatory policies in the EU and elsewhere have limited the number of GE crops

80 and traits developed globally ${ }^{12}$. Which crops have commercialized GE varieties is clearly

81 impacted by the economic demands of countries that permit them. The fact that soybean,

82 maize, and cotton are among the most widely-grown crops in the USA has certainly driven the

83 creation of their GE varieties. By contrast, the most widely grown crops in the EU — wheat and

84 barley - have no commercialized GE varieties, but this could change if European scientists had

85 a market to work toward, particularly since Northwest Europe has levels of wheat crop losses

86 due to pests and diseases that are above the global average ${ }^{13}$.

88 European researchers have argued repeatedly against the EU's reticence to accept GE crops ${ }^{14}$.

89 However, the EU may be headed in the opposite direction, as the new Farm-to-Fork Strategy

90 under the European Green Deal aims to expand organic farming, which has lower yields and

91 would be associated with significant increases in global GHG emissions through causing land-

92 use change elsewhere ${ }^{15}$. Rather than offshoring environmental damage to other nations, as the

93 European Green Deal does, the EU should increase agricultural productivity through embracing

94 new crop technologies, thus contributing to global environmental benefits ${ }^{16}$.

96 There is reason to be hopeful. As crop biotechnology research continues, a wider variety of

97 traits will become available, each with different yield impacts. Similar to IR and HT, GE crops

98 tolerant to other stressors such as drought and heat will improve effective yields through

99 reduced crop damage. Possibly more dramatic yield increases could come from GE traits that

100 improve yield potential through enhanced plant growth and photosynthetic efficiency ${ }^{17}$. New

101 gene editing technologies will likely further increase the diversity of desirable crop-trait

102 combinations ${ }^{12}$. Larger yield increases in more crops would lead to larger GHG emission 
bioRxiv preprint doi: https://doi.org/10.1101/2021.02.10.430488; this version posted February 10, 2021. The copyright holder for this preprint

(which was not certified by peer review) is the author/funder, who has granted bioRxiv a license to display the preprint in perpetuity. It is made available under aCC-BY 4.0 International license.

103 reductions. Hence, our estimate of $33 \mathrm{MtCO}_{2} \mathrm{e} / \mathrm{yr}$ is only a small proportion of the potential future

104 benefits of GE crops for climate change mitigation. 


\section{Methods}

Countries analyzed. We consider the EU with 28 member countries, before Brexit, as our analysis refers to 2017 as the base year.

Crops analyzed. We include the five GE crops with the highest adoption rates in the USA (soybean, maize, cotton, canola, and sugarbeet), which includes the three most widely grown

111 GE crops worldwide (soybean, maize, and cotton) plus two grown especially in the cooler

112 temperate-zone climates of North America (canola and sugarbeet). In the EU, all soybean,

113 cotton, canola and sugarbeet grown are non-GE varieties, and all but a tiny proportion of maize

114 grown in the EU is non-GE varieties.

Area cultivated and historical crop yields. For the total area cultivated for each crop and for historical crop yields, we use FAOSTAT data for the EU28 special grouping from 2017

118 (Supplementary Table 1).

Adoption rates. In the four countries that plant the most GE crops worldwide — USA, Brazil, 121 Argentina, and Canada - adoption rates for soybean, maize, cotton, canola, and sugarbeet 122 range from 85-100\%; we use adoption rates from the USA in $2017^{7}$ (Supplementary Table 1). 123 As a robustness check, we re-calculate total avoided GHG emissions using lower adoption rates 124 of $85 \%$ (the low end of all adoption rates in the top-four GE-growing countries worldwide) and $12550 \%$ (a much lower adoption rate that might represent a country midway through increasing 126 adoption). With $85 \%$ and 50\% adoption for all five crops, total avoided GHG emissions are 30 127 and $17 \mathrm{MtCO}_{2} \mathrm{e} / \mathrm{yr}$, respectively.

129 Yield benefits of GE traits. We use data from a global meta-analysis of GE crop impacts to 130 estimate yield increases ${ }^{8}$. Yield effects vary by geographic region. As we are interested in 
131 potential effects in the EU, we only consider the data from temperate-zone industrialized

132 countries, not from developing countries where yield effects tend to be higher. We consider yield

133 effects of IR and HT crops separately. For GE varieties with stacked IR and HT traits, we add

134 the individual yield benefits. This assumption is reasonable, as insect pests and weeds cause

135 separate yield damage, and farmers make decisions about insecticide and herbicide sprays

136 independently. In their global analysis of GE crop impacts, Brookes and Barfoot (2020) also

137 added the benefits of stacked IR and HT traits. As an additional robustness check, we calculate

138 total avoided emissions using a lower value for the yield benefit of stacked traits - just the yield

139 benefit from the IR trait, rather than adding the effects from IR and HT traits. This is only

140 relevant for maize and cotton, as these two crops are the only ones for which stacked traits are

141 available. Total avoided emissions in this alternative scenario are $25 \mathrm{MtCO}_{2} \mathrm{e} / \mathrm{yr}$.

143 Fertilizer application. We use 2011 data on nitrogen fertilizer application per hectare by

144 country and crop from Zhang (2015) in addition to 2011 FAOSTAT data for the area of each

145 crop harvested in individual EU countries. We summed the Zhang (2015) data for total nitrogen

146 applied across all EU countries represented for each crop, then divided by the sum of the areas

147 harvested from all EU countries that grew that crop (Supplementary Table 2). We incorporated

148 this EU average value for nitrogen applied per hectare of each crop into the site-specific

149 production emissions (PEM).

151 Site-specific PEM. For the PEM (production emissions) component of calculating total avoided

152 emissions, we used tabs 3.1 and 3.2 of the Searchinger (2018) Carbon Benefits Calculator.

153 Users may enter site-specific values for all or a subset of fertilizer application, on-farm energy

154 use, and energy use to produce fertilizer and pesticides. We entered site-specific values only for

155 fertilizer application, and used default values for energy use because this component of total

156 emissions only makes a small contribution compared to COC, so further site-specific values 
157 would make only a small difference in total emissions reductions. We used the default $\mathrm{CO}_{2} \mathrm{e} / \mathrm{N}$

158 input, and we did not input values for rice methane. Site-specific changes in fuel use could also

159 incorporate decreases due to reduced tilling and pesticide application, as calculated by Brookes

160 and Barfoot (2020).

162 Carbon Benefits Calculator. In order to calculate the total potential for avoided emissions from

163 GE yield increases, we used tabs 1, 3.1, and 3.2 (the latter two as described above for PEM) of

164 the Searchinger et al. (2018) Carbon Benefits Calculator to compute the avoided GHG

165 emissions from the higher yields with GE varieties compared to the 2017 conventional yields per

166 hectare of each crop. We used the default COC for each crop with the default $4 \%$ discount rate,

167 fresh matter as the weight type for all variables, and did not enter inputs for livestock or

168 bioenergy. Then we multiplied this difference by the total area of that crop harvested across the

169 EU in 2017 adjusted for the assumed GE adoption rate.

171 Acknowledgements

172 We thank Kenton de Kirby for providing valuable comments on the manuscript.

\section{Author contributions}

175 DBR conceived the study, contributed to methods, and contributed to editing. EK contributed to

176 methods, implemented the analysis, wrote the manuscript, and contributed to editing. MQ

177 provided data and contributed to interpreting the results and to editing.

\section{Competing Interests Statement}

180 The authors declare no competing interests.

\section{References}


1. Qaim, M. Role of New Plant Breeding Technologies for Food Security and Sustainable Agricultural Development. Applied Economic Perspectives and Policy 42, 129-150 (2020).

2. Smyth, S. J. The human health benefits from GM crops. Plant Biotechnology Journal 18, 887-888 (2020).

3. Brookes, G. \& Barfoot, P. Environmental impacts of genetically modified (GM) crop use 1996-2018: impacts on pesticide use and carbon emissions. GM Crops and Food 11, 215-241 (2020).

4. Folberth, C. et al. The global cropland-sparing potential of high-yield farming. Nature Sustainability 3, 281-289 (2020).

5. Searchinger, T. et al. Creating A Sustainable Food Future. Agency for International Development https://www.wri.org/our-work/project/world-resources-report/publications. (2018).

6. Searchinger, T. D., Wirsenius, S., Beringer, T. \& Dumas, P. Assessing the efficiency of changes in land use for mitigating climate change. Nature 564, 249-253 (2018).

7. ISAAA. Brief 53: Global Status of Commercialized Biotech/GM Crops in 2017. (2017).

8. Klümper, W. \& Qaim, M. A meta-analysis of the impacts of genetically modified crops. PLOS ONE 9, (2014).

9. Fourth Biennial Report from the European Union under the United Nations Framework Convention on Climate Change. (2019).

10. Rodriguez Garcia, V., Gaspart, F., Kastner, T. \& Meyfroidt, P. Agricultural intensification and land use change: assessing country-level induced intensification, land sparing and rebound effect. Environmental Research Letters (2020).

11. Villoria, N. B., Byerlee, D. \& Stevenson, J. The effects of agricultural technological progress on deforestation: What do we really know? Applied Economic Perspectives and Policy 36, 211-237 (2014).

12. Whelan, A. I., Gutti, P. \& Lema, M. A. Gene Editing Regulation and Innovation Economics. Frontiers in Bioengineering and Biotechnology 8, (2020).

13. Savary, S. et al. The global burden of pathogens and pests on major food crops. Nature Ecology and Evolution 3, 430-439 (2019).

14. German National Academy of Sciences Leopoldina, Union of the German Academies of Sciences and Humanities \& German Research Foundation. Towards a scientifically justified, differentiated regulation of genome edited plants in the EU. (2019).

15. Smith, L. G., Kirk, G. J. D., Jones, P. J. \& Williams, A. G. The greenhouse gas impacts of converting food production in England and Wales to organic methods. Nature Communications 10, (2019).

16. Fuchs, R., Brown, C. \& Rounsevell, M. Europe's Green Deal offshores environmental damage to other nations. Nature 586, 671-673 (2020).

17. Bailey-Serres, J., Parker, J. E., Ainsworth, E. A., Oldroyd, G. E. D. \& Schroeder, J. I. Genetic strategies for improving crop yields. Nature 575, 109-118 (2019).

18. Zhang, X. et al. Managing nitrogen for sustainable development. Nature 528, 51-59 (2015). 


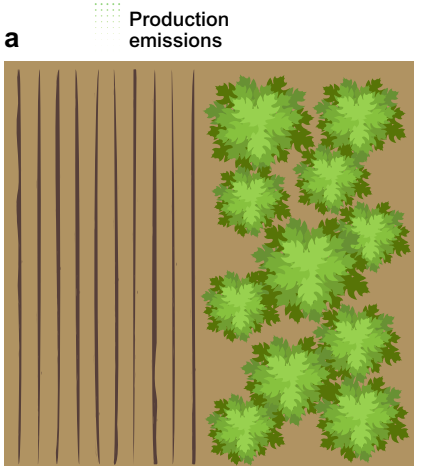

Baseline agricultural production

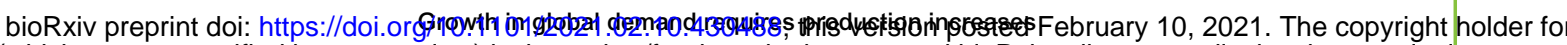
(which was not certified by peer review) is the authorffunder, who has granted bioRxiv a license to display the preprint in perpetu available under aCC-BY 4.0 International license.
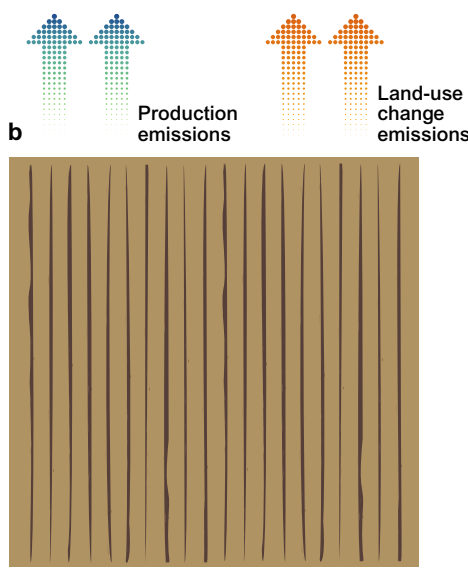

No yield increase
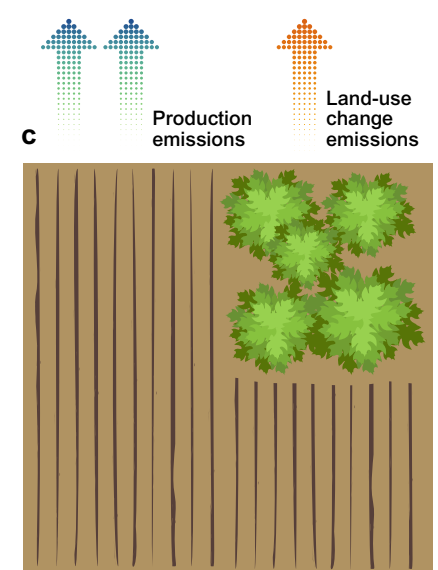

Moderate yield increas

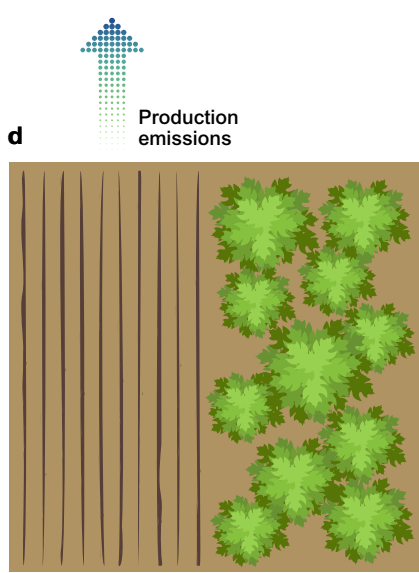

High yield increase

Fig. 1 | Increasing crop yields decrease the land conversion needed for agricultural production. This representation is simplified, as land use change and land sparing usually happen in a different location than original production. (a) Baseline agricultural production, which happens on a given amount of cropland with production-related GHG emissions. The rest of the land has native vegetation (forest, wetland, grassland, etc.). (b) Increased agricultural production without yield increase entails high conversion of natural land into cropland, with high land-use change emissions and increased production emissions. (c) Increased production with moderate yield increase results in moderate land-use change emissions and increased production emissions. (d) Increased production with high yield increase can help prevent both land-use change emissions and additional production emissions.

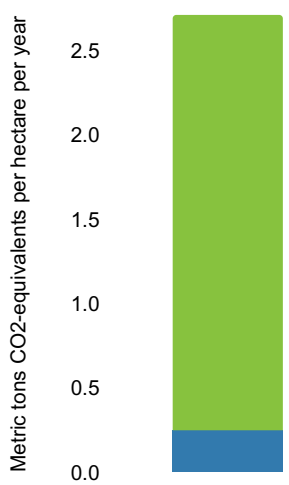

0.0

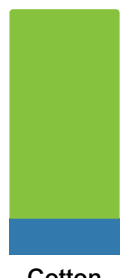

Cotton

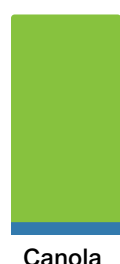

Canola

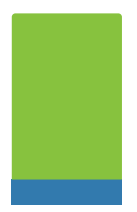

Sugarbeet

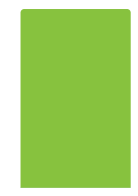

Soy

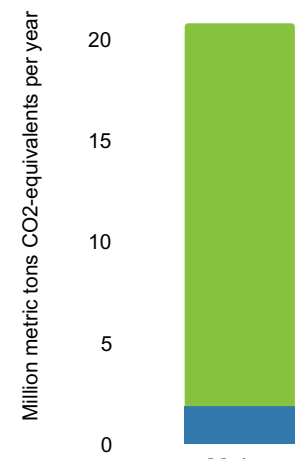

Maize

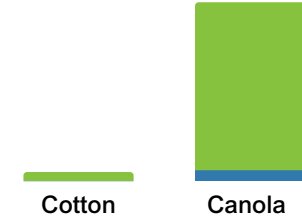

Sugarbeet 